Jurdimas (Jurnal Pengabdian Kepada Masyarakat) Royal

Vol. 4 No. 2, Mei 2021, hlm. 127 - 134

Available online at https://jurnal.stmikroyal.ac.id/index.php/jurdimas

\title{
PERBAIKAN PROSES PRODUKSI DAN PENINGKATAN PEMASARAN PADA UKM PUTRI TIMUS DI KARANGANYAR
}

\author{
Ida Giyanti $^{1^{*}}$, Erni Suparti ${ }^{1}$, Sunardi $^{2}$, Sugiarti $^{3}$ \\ ${ }^{1}$ Program Studi Teknik Industri, Fakultas Teknik, Universitas Setia Budi \\ ${ }^{2}$ Program Studi Analis Kimia, Fakultas Teknik, Universitas Setia Budi \\ ${ }^{3}$ Program Studi Akuntansi, Fakultas Ekonomi, Universitas Setia Budi \\ email:*idagiyanti@setiabudi.ac.id
}

\begin{abstract}
Timus is one of the famous traditional foods in the Central Java region. Putri Timus is one of the Small Medium Enterprise (SME) in Karanganyar district producing purple Timus. Timus from Putri Timus have one special feature, in which in the inside of the Timus contains Bligo (Benincasa hispida) fruit with various benefits. Although Putri Timus has product differentiation, product by Putri Timus is not well known to the public. The production process was carried out on a home scale and has not fully implemented production standards based on the criteria for Good Food Manufacturing Practices for Home Industry (CPPB-IRTP). This community service program aims to help Putri Timus to implement hygiene requirements in food production based on CPPB-IRTP criteria and increase its marketing capacity. The method used to solve the problems were training of Good Food Manufacturing Practice, improvement of production place, facilitation of production cloths and promotional media. The results obtained after community service activities related to the production aspect were increasing knowledge regarding good food production process and improvement of production place. Regarding the marketing aspect, several promotional media have been installed. In addition, there was also an increasing of sales and profit.
\end{abstract}

Keywords: traditional food; small medium enterprise; production; marketing

\begin{abstract}
Abstrak: Timus adalah salah satu makanan tradisional yang terkenal di Jawa Tengah. Putri Timus adalah salah satu Usaha Kecil Menengah di kabupaten Karanganyar yang memproduksi timus ungu. Produk dari Putri Timus memiliki satu keistimewaan yakni bagian dalam timus berisi buah Bligo (Benincasa hispida) dengan beragam manfaat. Meskipun produk memiliki diferensiasi, timus isi Bligo hasil produksi Putri Timus belum cukup dikenal masyarakat. Proses produksi dilakukan dalam skala rumahan dimana Putri Timus belum sepenuhnya menerapkan standar produksi berdasarkan kriteria Cara Produksi Pangan yang Baik - Industri Rumah Tangga Pangan (CPPB-IRTP). Program pengabdian masyarakat ini bertujuan membantu Putri Timus untuk dapat menerapkan syarat higiene dalam produksi pangan berdasarkan kriteria CPPB-IRTP serta meningkatkan kapasitas pemasaran. Metode yang digunakan untuk mengatasi permasalahan mitra ialah melalui penyuluhan tentang CPPB-IRTP, pembenahan tempat produksi, fasilitasi pakaian produksi dan media promosi. Hasil yang diperoleh setelah kegiatan pengabdian terkait aspek produksi ialah adanya peningkatan pengetahuan karyawan tentang CPPB-IRTP dan perbaikan tempat produksi yang lebih bersih dan layak. Terkait aspek pemasaran, beberapa media promosi telah dibuat dan dipasang. Selain itu juga terdapat peningkatan jumlah penjualan dan laba dari hasil penjualan timus.
\end{abstract}

Kata kunci: makanan tradisional; produksi; pemasaran; usaha kecil dan menengah. 
Jurdimas (Jurnal Pengabdian Kepada Masyarakat) Royal

Vol. 4 No. 2, Mei 2021, hlm. 127 - 134

ISSN 2614-7912 (Print)

DOI: https://doi.org/10.33330/jurdimas.v4i2.952

ISSN 2622-3813 (Online)

Available online at https://jurnal.stmikroyal.ac.id/index.php/jurdimas

\section{PENDAHULUAN}

Karanganyar merupakan salah satu daerah penghasil utama ubi jalar. Hal ini menjadi tantangan bagi masyarakat di sekitar Karanganyar untuk mengembangkan kuliner berbahan dasar ubi jalar. Salah satu makanan khas berbahan baku ubi jalar yang selama ini dikembangkan di Karanganyar adalah timus. Timus ialah ubi jalar yang direbus, dihaluskan dan dicampur pemanis kemudian digoreng (Nurhayati, Mulyana, Ekowati, \& Meilawati, 2014). Putri Timus merupakan usaha kecil menengah (UKM) yang fokus memproduksi timus ungu. Timus hasil olahan Putri Timus memiliki keunikan tersendiri, yaitu bagian dalam timus berisi buah bligo (Benincasa hispi$d a)$.

Meskipun produk Putri Timus memiliki diferensiasi dibandingkan timus pada umumnya, namun hasil produksi Putri Timus belum cukup dikenal masyarakat Karanganyar apalagi luar kota. Produk UKM Putri Timus selama ini dititipkan di pusat oleh-oleh yang telah terkenal di Karanganyar. Timus dikirim pada pagi hari, kemudian hari berikutnya dilakukan pengecekan stok timus. Untuk memperluas jangkauan pasar, Putri Timus terkendala dengan belum adanya Sertifikat Produksi Pangan Industri Rumah Tangga (SPP-IRT) dari Dinas Kesehatan Kabupaten Karanganyar. Padahal, dalam Pasal 43 Peraturan Pemerintah Nomor 28 Tahun 2004 Tentang Keamanan, Mutu, dan Gizi Pangan dijelaskan bahwa pangan olahan yang diproduksi oleh industri rumah tangga wajib memiliki SPP-IRT. SPP-IRT juga dapat digunakan sebagai media bagi pelaku UKM untuk memperluas pasar produknya.

Selain itu, belum adanya ijin SPP-

IRT menimbulkan kekhawatiran bagi pemilik Putri Timus karena jika produk belum memiliki ijin edar maka jika sewaktu-waktu dinas terkait melakukan inspeksi, produk tanpa ijin edar tersebut bisa ditarik dari pasar. Untuk mendapatkan ijin edar SPP-IRT, proses produksi yang dilakukan Putri Timus harus memenuhi syarat higiene sebagaimana disebutkan dalam pedoman Cara Produksi Pangan yang Baik - Industri Rumah Tangga Pangan (CPPB-IRTP). CPPBIRTP berisikan beberapa indikator mengenai sanitasi yang baik dalam operasional produksi oleh industri rumah tangga atau usaha kecil menengah. Dengan berpedoman pada CPPB-IRTP diharapkan industri kecil dan menengah mampu memproduksi pangan yang berkualitas, layak konsumsi, dan aman bagi kesehatan (BPOM RI, 2012). Permasalahan tentang keamanan pangan masih banyak ditemui di industri kecil dan menengah karena praktik sanitasi dan kebersihan yang kurang baik (Arkeman, Herlinawati, Wibawa, \& Adinegoro, 2015). Begitu juga halnya yang dialami oleh Putri Timus. Hal ini dapat dilihat dari ruang produksi yang belum memenuhi standar sebagaimana disyaratkan dalam CPPB-IRTP. Faktor lain ialah yang berkaitan dengan higiene karyawan produksi dimana selama ini karyawan bagian produksi yang kontak langsung dengan pangan tidak menggunakan baju produksi, masker, dan sarung tangan.

Agar dapat bersaing di pasaran, pelaku IRT dan karyawannya perlu diberikan edukasi tentang pentingnya proses produksi pangan yang higienis (Anggraini \& Yudhastuti, 2014). Salah satu pedoman tentang proses produksi pangan yang higienis bagi IRT ialah CPPB-IRTP. Penerapan CPPB-IRTP diyakini mampu meningkatkan daya saing IRT di era pasar bebas (Herlambang, Asmawati, \& Haryono, 2018). Oleh ka- 
rena itu, program pengabdian masyarakat ini bertujuan membantu Putri Timus untuk dapat menerapkan syarat higiene dalam produksi pangan berdasarkan kriteria CPPB-IRTP serta meningkatkan kapasitas pemasaran.

\section{METODE}

Permasalahan mendasar yang dihadapi oleh Putri Timus ialah terkait aspek produksi dan pemasaran. Kedua permasalahan tersebut saling terkait, dimana pembenahan pada aspek produksi akan berpengaruh terhadap aspek pemasaran (Anggraini \& Yudhastuti, 2014; Herlambang, Asmawati, \& Haryono, 2018). Metode penyelesaian masalah untuk setiap aspek berbeda.

Tahapan pelaksanaan kegiatan pengabdian masyarakat dimulai dari tahap persiapan, tahap pelaksanaan, dan tahap pemantauan. Tahap persiapan berupa koordinasi internal tim pengabdian maupun koordinasi dengan mitra dan pihak lain yang terkait dengan programprogram pengabdian yang akan dilakukan.

Tabel 1. Solusi Permasalahan dan Target Luaran

\begin{tabular}{|c|c|c|}
\hline Permasalahan & Solusi & Target Luaran \\
\hline \multirow[t]{2}{*}{$\begin{array}{l}\text { UKM Putri Timus be- } \\
\text { lum memiliki penge- } \\
\text { tahuan dasar tentang } \\
\text { CPPB-IRTP }\end{array}$} & 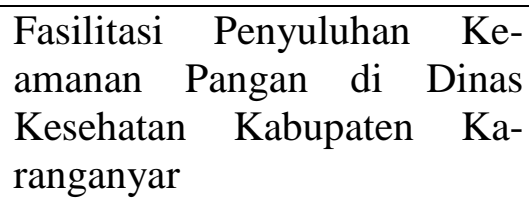 & $\begin{array}{l}\text { Putri Timus memiliki Ser- } \\
\text { tifikat Penyuluhan Ke- } \\
\text { amanan Pangan dengan } \\
\text { predikat Lulus }\end{array}$ \\
\hline & $\begin{array}{l}\text { Studi banding ke UKM se- } \\
\text { jenis yang telah menerapkan } \\
\text { prinsip CPPB-IRTP }\end{array}$ & $\begin{array}{l}\text { Putri Timus mendapatkan } \\
\text { gambaran riil praktek } \\
\text { CPPB-IRTP }\end{array}$ \\
\hline $\begin{array}{l}\text { Ruang produksi belum } \\
\text { memenuhi syarat hi- } \\
\text { giene }\end{array}$ & Pembenahan ruang produksi & $\begin{array}{l}\text { Ruang produksi bersih dan } \\
\text { layak untuk produksi } \\
\text { produk pangan }\end{array}$ \\
\hline $\begin{array}{l}\text { Karyawan tidak me- } \\
\text { makai pakaian produksi } \\
\text { saat bersentuhan lang- } \\
\text { sung dengan produk } \\
\text { pangan }\end{array}$ & $\begin{array}{l}\text { Fasilitasi dan pembiasaan un- } \\
\text { tuk menggunakan pakaian } \\
\text { produksi, masker dan sarung } \\
\text { tangan kepada karyawan }\end{array}$ & $\begin{array}{l}\text { Seluruh karyawan telah } \\
\text { memakai pakaian } \\
\text { produksi dan masker saat } \\
\text { memproduksi timus }\end{array}$ \\
\hline \multirow[t]{3}{*}{$\begin{array}{l}\text { Produk timus isi Bligo } \\
\text { belum cukup dikenal } \\
\text { luas oleh masyarakat }\end{array}$} & $\begin{array}{l}\text { Bantuan papan petunjuk arah } \\
\text { menuju lokasi UKM Putri } \\
\text { Timus }\end{array}$ & $\begin{array}{l}\text { Papan petunjuk arah sudah } \\
\text { terpasang }\end{array}$ \\
\hline & $\begin{array}{l}\text { Bantuan neon box dan mini } \\
\text { poster varian produk Putri } \\
\text { Timus agar masyarakat } \\
\text { mengenal alamat rumah } \\
\text { produksi Putri Timus }\end{array}$ & $\begin{array}{l}\text { Neon box dan poster } \\
\text { produk Putri Timus } \\
\text { terpasang di depan rumah } \\
\text { produksi Putri Timus }\end{array}$ \\
\hline & $\begin{array}{l}\text { Pembuatan brosur tentang } \\
\text { produk Putri Timus }\end{array}$ & $\begin{array}{l}\text { Brosur sudah tercetak dan } \\
\text { didistribusikan pada saat } \\
\text { ada even bazar UKM }\end{array}$ \\
\hline
\end{tabular}


Available online at https://jurnal.stmikroyal.ac.id/index.php/jurdimas

Pada Tabel 1, merupakan solusi serta target luaran yang diharapkan untuk setiap permasalahan yang ada di Putri Timus. Pada tahap persiapan juga dilakukan pembagian tugas untuk setiap tim pengabdian. Tahap pelaksanaan ialah eksekusi atas program-program yang telah direncanakan. Tahap pemantauan berupa evaluasi pencapaian terhadap program-program yang direncanakan. Tolok ukur pada tahap evaluasi ialah capaian target luaran sebagaimana yang telah direncanakan (Tabel 1).

\section{PEMBAHASAN}

Kegiatan pengabdian dimulai dengan tahap persiapan, yaitu koordinasi internal tim pengabdian untuk penyusunan rencana kegiatan dan pembagian tugas (Gambar 1). Koordinasi juga dilakukan dengan mitra pengabdian agar program-program yang telah direncanakan dapat berjalan dengan lancar tanpa mengganggu proses produksi harian di UKM Putri Timus. Selain itu, tim pengabdian juga melakukan koordinasi dengan Dinas Kesehatan Kabupaten Karanganyar terkait syarat-syarat pengajuan ijin P-IRT dan CPPB-IRTP (Gambar 2).

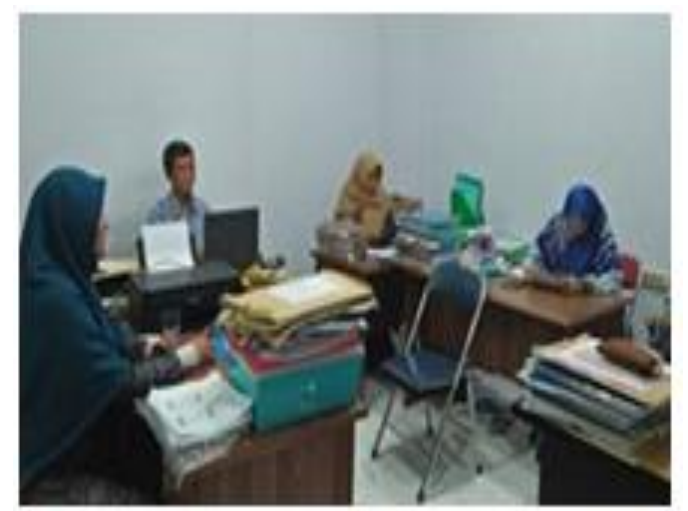

Gambar 1. Koordinasi Internal

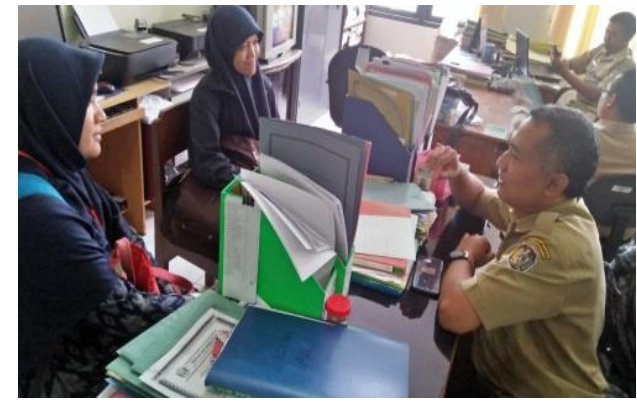

Gambar 2. Koordinasi dengan Dinas Kesehatan Kabupaten Karanganyar

Hasil yang dicapai selama pelaksanaan pengabdian masyarakat dijelaskan sebagai berikut. Kegiatan pertama ialah fasilitasi penyuluhan keamanan pangan. Tujuan kegiatan ini adalah agar pelaku UKM mengetahui pentingnya cara produksi pangan yang baik, sehingga akan menjaga kualitas produksi dan higienisme fasilitas produksi. Pemilik Putri Timus telah mengikuti Penyuluhan Keamanan Pangan yang diselenggarakan oleh Dinas Kesehatan Kabupaten Karanganyar. Pemilik Putri Timus juga telah memperoleh sertifikat Penyuluhan Keamanan Pangan (Gambar 3) yang menjadi salah satu syarat untuk pengajuan P-IRT.

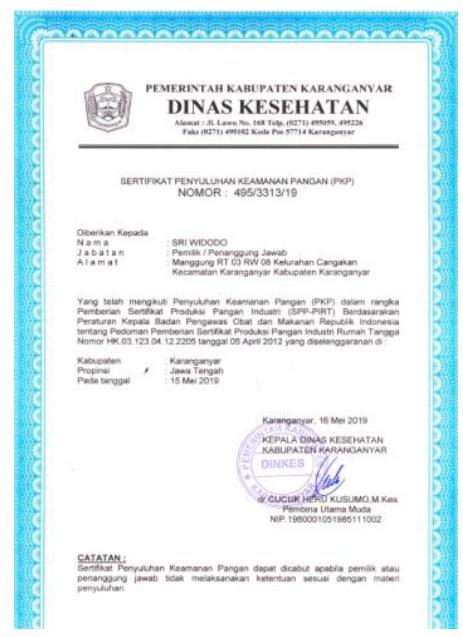

Gambar 3. Sertifikat Penyuluhan Keamanan Pangan 
Kegiatan kedua ialah studi banding implementasi CPPB-IRTP (Gambar 4). Kegiatan dilakukan dengan melakukan studi banding pada UKM serupa yang sudah lebih maju yaitu Gethuk Take. Selain melihat di lapangan secara langsung sistem produksi yang sudah baik, pelaku UKM memperoleh arahan bagaimana melakukan produksi yang baik. Putri Timus sangat antusias mengikuti kegiatan dengan mengajukan beberapa pertanyaan seputar CPPB-IRTP.

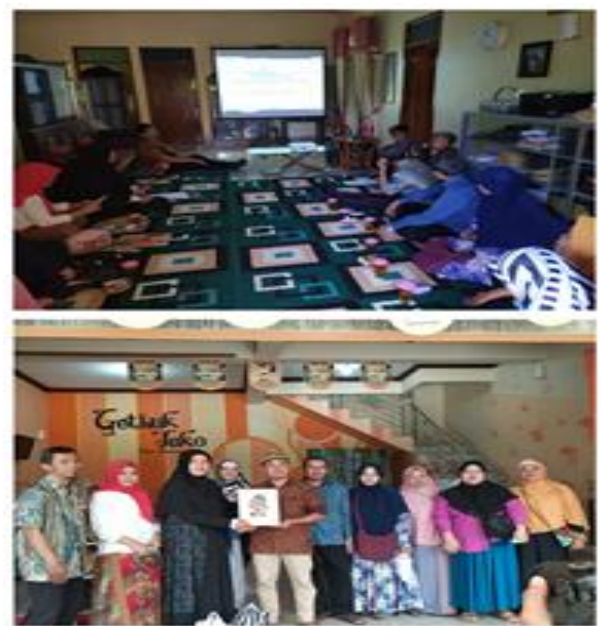

Gambar 4. Studi Banding CPPB-IRTP di UKM Gethuk Take

Kegiatan ketiga yaitu pembenahan ruang produksi. Selama ini ruang produksi di Putri Timus masih berlantai tanah dan dinding ruang produksi juga terkesan kotor. (Gambar 5).
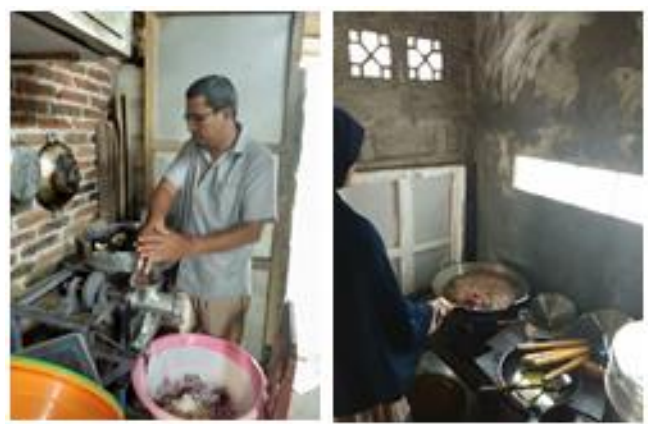

Gambar 5. Ruang Produksi Sebelum Perbaikan
Hal ini tidak sesuai dengan kriteria dalam CPPB-IRTP. Tim pengabdian kemudian melakukan pembenahan ruang produksi agar memenuhi syarat CPPBIRTP yaitu bersih dari debu, sarang labalaba, dan kotoran lainnya. Karena produk khas Putri Timus adalah timus ungu, maka ruang produksi diubah dengan nuansa ungu untuk mencerminkan produk inti dari UKM Putri Timus (Gambar 6).
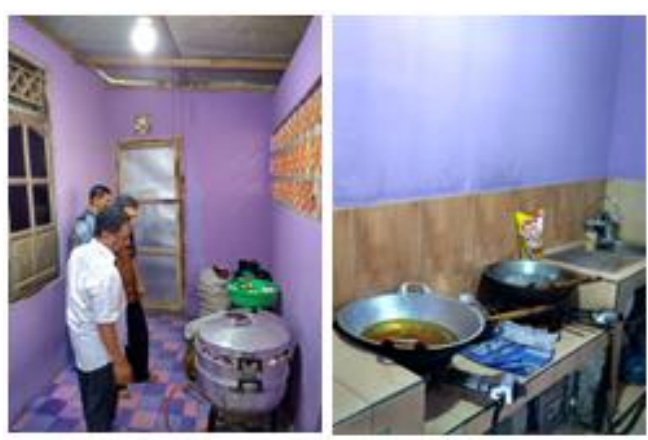

Gambar 6. Ruang Produksi Setelah Perbaikan

Kegiatan keempat adalah fasilitasi pakaian produksi. Selama ini karyawan Putri Timus saat melakukan produksi dan kontak langsung dengan bahan pangan tidak memakai pakaian produksi (Gambar 7).
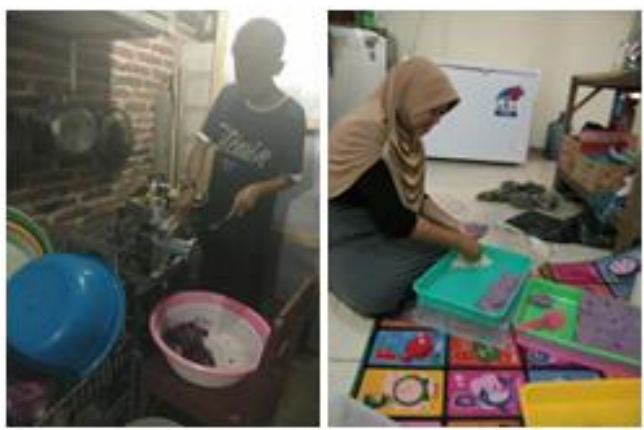

Gambar 7. Karyawan Tidak Memakai Pakaian Produksi

Sesuai syarat dalam CPPB-IRTP, pakaian produksi dapat berupa celemek, sarung tangan, dan masker (BPOM RI, 2012). Untuk itu, tim pengabdian memberikan 
Jurdimas (Jurnal Pengabdian Kepada Masyarakat) Royal

Vol. 4 No. 2, Mei 2021, hlm. 127 - 134

DOI: https://doi.org/10.33330/jurdimas.v4i2.952

Available online at https://jurnal.stmikroyal.ac.id/index.php/jurdimas

bantuan kepada karyawan Putri Timus berupa pakaian produksi dan mengedukasi kepada karyawan untuk membiasakan menggunakan pakaian kerja selama melakukan kegiatan produksi terutama saat bersentuhan langsung dengan bahan pangan (Gambar 8).

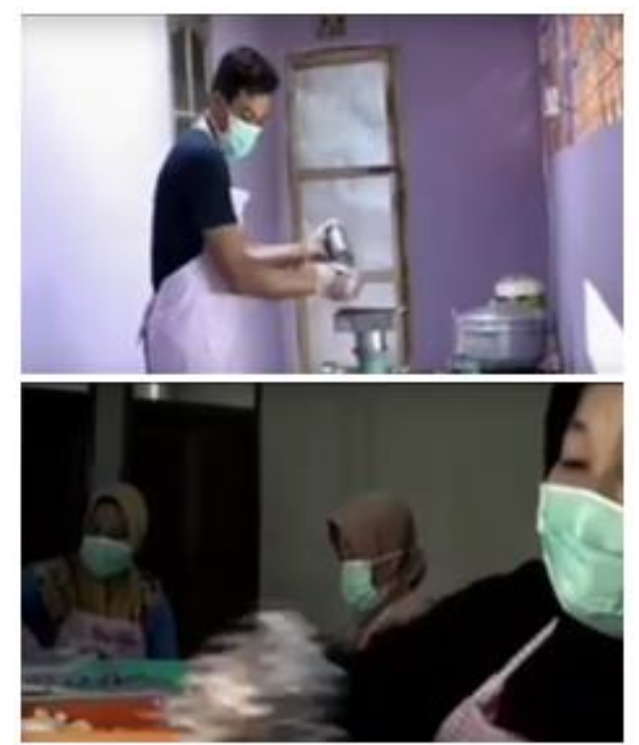

Gambar 8. Karyawan Telah Memakai Pakaian Produksi

Kegiatan kelima ialah desain brosur, poster, neon box dan papan penunjuk arah menuju rumah produksi Putri Timus yang bertujuan untuk membantu meningkatkan pasar Putri Timus. Brosur berisi sekilas tentang Putri Timus, varian produk serta narahubung untuk pemesanan produk timus (Gambar 9). Poster berisi varian produk ditempel di sisi samping rumah produksi sehingga masyarakat dapat mengenali varian produk Putri Timus (Gambar 10). Neon box dipasang di depan rumah produksi Putri Timus sehingga masyarakat mengetahui dengan pasti lokasi produksi Putri Timus (Gambar 11). Papan petunjuk arah dipasang di jalan raya untuk memudahkan masyarakat mengenali lokasi $\mathrm{Pu}-$ tri Timus (Gambar 12).

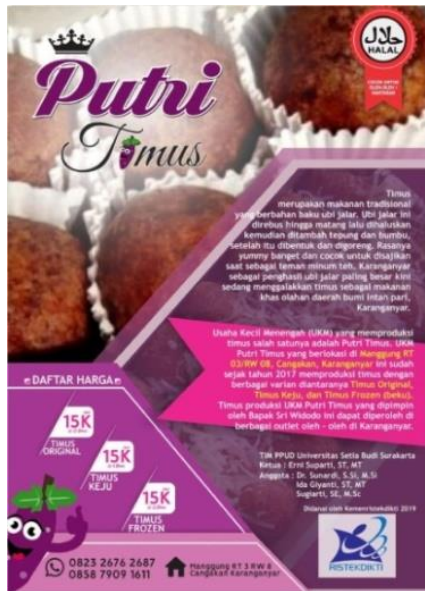

Gambar 9. Brosur Putri Timus

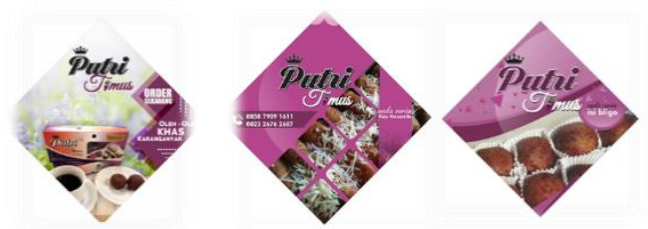

Gambar 10. Poster Varian Produk Putri Timus

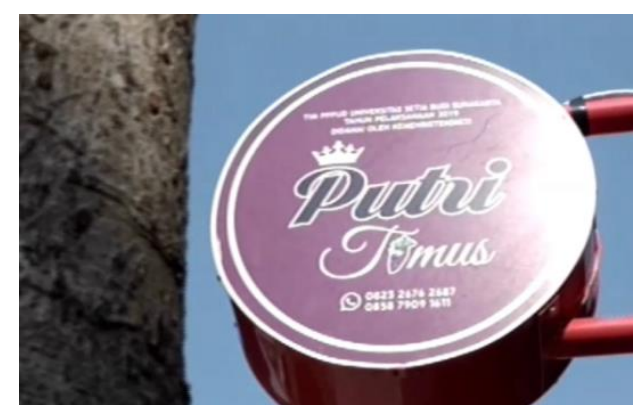

Gambar 11. Neon Box yang Dipasang di Depan Rumah Produksi

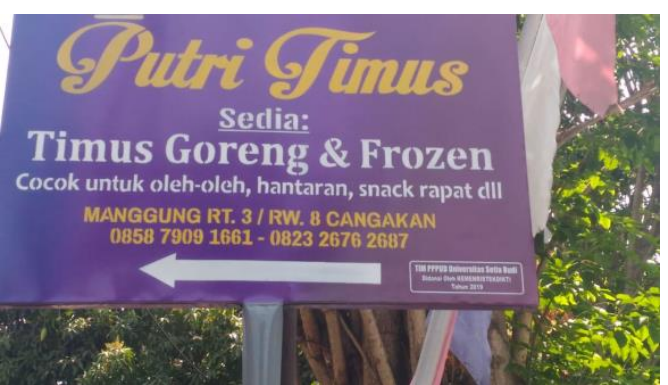

Gambar 12. Papan Petunjuk Arah

Setelah kegiatan pengabdian masyarakat, mitra mengalami peningkatan pengetahuan tentang CPPB-ITRP dan juga 
Available online at https://jurnal.stmikroyal.ac.id/index.php/jurdimas

mengalami peningkatan dalam hal penjualan produk. Grafik perbandingan omset dan laba sebelum dan sesudah pendampingan ditampilkan pada Gambar 13 dan Gambar 14. Peningkatan omset menggambarkan bahwa Putri Timus mulai dikenal oleh masyarakat di wilayah Karanganyar dan sekitarnya. Putri Timus juga mulai mendapatkan pesanan untuk acara besar seperti pernikahan, oleh- oleh guru/pegawai, kudapan rapat, atau arisan.

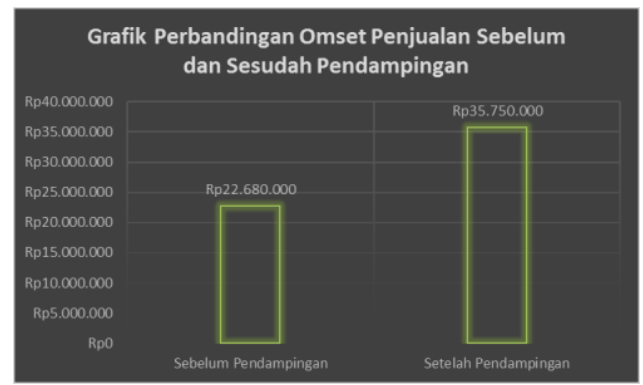

Gambar 13. Perbandingan Omzet

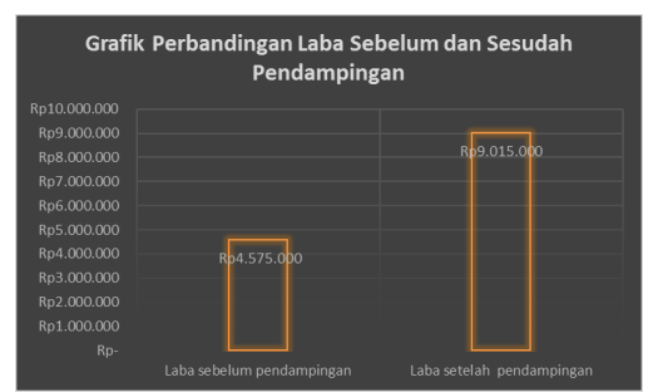

Gambar 14. Perbandingan Laba Bersih

Setelah pendampingan dalam hal produksi dan pemasaran, UKM Putri Timus menunjukkan kemajuan yang baik. Meskipun perbaikan pada aspek produksi belum mencakup seluruh indikator dalam CPPB-IRTP, namun praktek dan kebiasaan produksi pangan yang bersih dan aman telah menjadi kebiasaan di UKM Putri Timus. Hal ini sesuai dengan hasil pengabdian masyarakat yang dilakukan oleh (Asih \& Arsil 2019) dimana perilaku karyawan terhadap praktek CPPBIRTP mengalami peningkatan yang awalnya masih negatif menjadi bernilai baik. Dari segi pemasaran, selain UKM peningkatan omset dan laba sebagaimana pengabdian yang dilakukan oleh (Ningsih, Kintoko, \& Putri, 2020) dan (Herlambang, Asmawati, \& Haryono, 2018), UKM Putri Timus juga mulai dikenal oleh dunia pendidikan sebagai tempat outing class. Dalam kurun waktu pelaksanaan pengabdian, terdapat beberapa sekolah dan kampus yang melakukan acara outing class ke UKM Putri Timus. Siswa dari beberapa SMA dan mahasiswa dari kampus mendapat tugas untuk melihat perkembangan industri kreatif di Karanganyar. Pelajar yang pernah berkunjung antara lain berasal dari SMAIT Al Hikmah, SMA Negeri 2 Karanganyar, Mahasiswa Universitas Muhammadiyah Surakarta (UMS), dan Mahasiswa Universitas Setia Budi (USB) Surakarta.

\section{SIMPULAN}

Tujuan pengabdian ini adalah memperbaiki proses produksi di UKM Putri Timus sesuai persyaratan cara produksi pangan yang baik serta untuk meningkatkan kapasitas pemasaran. Perbaikan pada aspek produksi dilakukan melalui pelatihan tentang CPPB-IRTP serta praktek implementasi beberapa indikator dalam CPPB-IRTP dengan memfasilitasi mitra dalam hal perbaikan tempat produksi dan bantuan pakaian produksi. Kegiatan pengabdian pada aspek pemasaran ialah berupa fasilitasi berbagai sarana promosi agar masyarakat mengenal produk Putri Timus. Setelah pendampingan, mitra mulai terbiasa dengan praktek CPPB-IRTP untuk memproduksi produk pangan yang aman. Sedangkan dari sisi pemasaran, produk Putri Timus mengalami peningkatan omset penjualan maupun laba. 
Jurdimas (Jurnal Pengabdian Kepada Masyarakat) Royal

Vol. 4 No. 2, Mei 2021, hlm. 127 - 134

DOI: https://doi.org/10.33330/jurdimas.v4i2.952

Available online at https://jurnal.stmikroyal.ac.id/index.php/jurdimas

\section{UCAPAN TERIMA KASIH}

Ucapan Terima kasih disampaikan kepada DRPM RISTEKDIKTI yang telah memberikan dana pengabdian kepada masyarakat pada tahun 2019 melalui skema PPPUD. Terima kasih juga disampaikan kepada UKM Putri Timus yang telah bekerjasama selama pelaksanaan program pengabdian sehingga program berjalan lancar, UKM Gethuk Take dan Dinas Kesehatan Kabupaten Karanganyar yang telah berbagi ilmu tentang teori dan praktik CPPB-IRTP.

\section{DAFTAR PUSTAKA}

Anggraini, T., \& Yudhastuti, R. (2014). Penerapan good manufactoring practices pada industri rumah tangga kerupuk teripang di Sukolilo Surabaya. Jurnal Kesehatan Lingkungan, 7(2), 148-158.

Arkeman, Y., Herlinawati, T., Wibawa, D. S., \& Adinegoro, H. (2015). FORMULATING STRATEGIES TO IMPROVE FOOD SAFETY OF BAKERY SMALL-MEDIUM ENTERPRISES THROUGH GOOD MANUFACTURING PRACTICE. Jurnal Teknologi Industri Pertanian, 25(1), 43-51.

Asih, E. R., \& Arsil, Y. (2019). Penerapan Cara Produksi Pangan
Yang Baik Pada IRT Bawang Goreng Kota Pekanbaru. Jurnal Pengabdian Dinamisia, 3(2), 221-227.

BPOM RI. (2012). Pedoman Cara Produksi Pangan yang Baik untuk Industri Rumah Tangga. Jakarta: BPOM RI.

Herlambang, A., Asmawati, E., \& Haryono, Y. (2018). Implementation of Good Food Production Method for Kerupuk Household Industry in Sidoarjo. Agrokreatif Jurnal Ilmiah Pengabdian Kepada Masyarakat, 4(1), 31. https://doi.org/10.29244/agrokreat if.4.1.31-37

Ningsih, S. C., Kintoko, \& Putri, P. H. (2020). Inovasi Kemasan dan Perluasan Pemasaran Usaha Rempeyek di Yogyakarta. Dinamisia: Jurnal Pengabdian Kepada Masyarakat, 4(1), 6-11. https://doi.org/10.31849/dinamisi a.v4i1.3268

Nurhayati, E., Mulyana, Ekowati, V. I., \& Meilawati, A. (2014). INVENTARISASI MAKANAN TRADISIONAL JAWA UNSUR SESAJI DI PASAR-PASAR TRADISIONAL KABUPATEN BANTUL. Jurnal Penelitian Humaniora, 19(2), 124-140. 